\title{
Performance and Effectiveness of Portable Air Cleaners in an Office Room: An Experimental Study
}

\author{
Siamak Rahimi Ardkapan, Alireza Afshari and Niels Christian Bergsøe \\ Department of Energy and Environment, Danish Building Research Institute, Aalborg University, Copenhagen 2450, Denmark
}

\begin{abstract}
Nowadays, many people work in an office environment. Air pollutants, including particles and gases, are generated by humans and by different devices that are used in offices. Pollutants can also enter an office room with the air supplied from outdoors. It has been established that air pollutants have adverse health effects on human body. Air cleaning devices are commonly marketed as being beneficial for the health by removing air pollutants and consequently improving indoor air quality. The performance of five air cleaning technologies was tested in order to determine the generation of ozone and particles in an office room. The particle removal effectiveness of the technologies was also determined in order to clarify their ability to remove UFPs (ultrafine particles) in the office room. The tested five air cleaning technologies are non-thermal plasma, corona discharge ionizer, portable air purifier, electrostatic fibrous filter and three-dimensional fibrous filter. The interior surfaces of the office room emit low levels of volatile organic compounds, since the office room has not been refurbished for about two decades. The results showed that the particle removal effectiveness of the technologies was ranged between 0.2 and 0.45 for the office room. The three technologies using/generating ozone significantly increased the ozone level in the office room. However, no increase of the UFP concentration was detected.
\end{abstract}

Key words: Air cleaning, particle, UFP, ozone.

\section{Introduction}

Numerous air pollutants including gasses and particles exist in an office environment. Photocopiers, laser printers and cleaning products in office buildings have been identified as indoor sources of UFPs (ultrafine particles) [1, 2]. Particles including coarse, fine and ultrafine particles have adverse health effects on human body [3-5].

Ultrafine particles can cause more inflammation in the lungs compared with larger particles [6, 7]. It has also been observed that the exposure to UFPs was associated with other health problems such as cardiovascular and depression problems [8-10].

In addition, gaseous pollutants in an office environment include VOCs (volatile organic compounds), carbon monoxide and ozone. Ozone is considered a toxic gas since it can cause adverse health effects in human body [11, 12].

Corresponding author: Siamak Rahimi Ardkapan, Ph.D., research fields: indoor air quality, fluid dynamics and ventilation systems. E-mail:sra@sbi.aau.dk.
Furthermore, ozone reacts with terpene and other unsaturated VOCs and generates UFPs [13, 14]. The unsaturated VOCs including terpene are emitted from different products, such as building materials and detergents [15]. The emission from building materials depends on several factors such as air velocity, temperature and the age of the building material $[16,17]$.

Air cleaning devices are commonly marketed as being good at eradicating air pollutants [18]. However, depending on the type of technology, they may generate some by-products such as ozone, and their effectiveness may differ depending on the type of technology [19, 20].

There is evidence that ozone generated by an air cleaner can react with unsaturated VOCs in the air and generate UFPs [21-26]. However, most of these studies involve laboratory environment with a constant ventilation rate and with wall materials of low VOC emission rates. The indoor air of an office room may be influenced by changes in the concentration of 
pollutants outdoors. In addition, an office room may contain some building materials and furniture that can add to the concentrations of VOCs, ozone and UFPs.

The aim of this study was to evaluate the effectiveness of air cleaners in an office environment with old wall material. The aim was also to assess the level of ozone generated by the air cleaners and the generated ozone's impact on the UFP concentration in this office room.

\section{Methods}

The experiments took place in an office room with dimensions of $4.8 \mathrm{~m} \times 3.3 \mathrm{~m} \times 3 \mathrm{~m}$. The office room was empty and located in an empty building. The walls of the room were painted and had windows on one side. The room had not been refurbished for two decades. The temperature and relative humidity of the room and outdoor temperature were logged continuously.

The measurements were accomplished during the winter, and they comprised two segments. First, each air cleaner operated individually in the office room in order to examine their performance. The UFP concentrations of indoor air and outdoor air were measured during the whole period of the experiments.

In the second segment of the measurements, the UFP removal effectiveness of each air cleaner was evaluated. In this segment of measurements, the particles were generated by a pure wax candle. As a first step, a candle was burnt in the room and after reaching steady-state concentration of UFPs in the room, it was extinguished. The removal rate of UFPs caused by the ventilation system and deposition was obtained by calculating the decay rate of the UFP concentration in the office room.

In order to obtain the removal rate of UFPs caused by each air cleaner together with the ventilation system, a candle was burnt again until reaching steady state. Then, the candle was extinguished and the air cleaner was turned on and ran continuously until the UFP concentration level reached the background level. By subtracting the two determined removal rates for UFPs and multiplying the subtracted value to the volume of the room, the CADR (clean air delivery rate) of the air cleaner was calculated [18].

Nazaroff [27] defined a dimensionless parameter as effectiveness $(\varepsilon)$ to compare the ability of the air cleaners to remove pollutants for a specific room. Air cleaner effectiveness is calculated using the following equation:

$$
\varepsilon=\frac{C A D R /\left[V\left(\lambda_{v}+\lambda_{d}\right)\right]}{1+C A D R /\left[V\left(\lambda_{v}+\lambda_{d}\right)\right]}
$$

where, $\lambda_{v}\left(\mathrm{~h}^{-1}\right)$ is the removal rate caused by ventilation, $\lambda_{d}\left(\mathrm{~h}^{-1}\right)$ denotes the removal rate caused by the deposition and $V\left(\mathrm{~m}^{3}\right)$ is the volume of the room. The effectiveness of an air cleaner showed how an air cleaner was effective at a specific ventilation rate [28].

In other words, the effectiveness is the ability of an air cleaner to reduce the exposure of humans to a pollutant, regardless of the air cleaner position in a room [29]. The effectiveness of the air cleaners was also evaluated in laboratory environments and residential buildings, but not in an office room [30-34].

The level of ozone in a room can be determined by a mass balance equation for ozone as shown in Eq. (2) [35]:

$$
V \frac{\mathrm{d} C}{\mathrm{~d} t}=G-\lambda_{o} V C
$$

where, $V$ is the volume of the room, $C(\mathrm{ppb})$ is the concentration of the ozone, $t$ is time and $\lambda_{o}\left(\mathrm{~h}^{-1}\right)$ is the decay rate of ozone due to all the mechanisms including deposition, removal by the filter of an air cleaner and the ventilation system, $G$ is the generation rate of ozone by an air cleaner.

In order to determine the $G$ value, the concentration of ozone before and after the air cleaner should be measured. Using the following equation, it is possible to determine $G$ which is in fact the amount of the ozone added to the volume of the room per unit of the time:

$$
G=F \times\left(C_{\text {outlet }}-C_{\text {inlet }}\right)
$$


where, $F$ is the flow rate of the air passing the air cleaner, $C_{\text {outlet }}$ is the ozone concentration at outlet and $C_{\text {intet }}$ is the ozone concentration at inlet.

Considering the background concentration of ozone equal to 0, then by integrating both sides of Eq. (2), the following equation can be determined:

$$
C=\frac{G}{\lambda_{o} V}\left(1-\mathrm{e}^{-\lambda_{o} t}\right)
$$

If the air cleaner works for an infinite time, then the exponential term will be 0 and Eq. (4) will be simplified as below and will give the maximum ozone concentration caused by the air cleaner in the room:

$$
C_{m}=\frac{G}{\lambda_{o} V}
$$

where, $C_{m}(\mathrm{ppb})$ is the maximum ozone concentration in the room. It is also possible to rearrange the equation to find the value of the ozone removal rate according to $C_{m}, G$ and $V$ :

$$
\lambda_{o}=\frac{G}{C_{m} V}
$$

Each air cleaner was located at the middle of the room on the floor. During all measurements, the air was well mixed by two small fans inside the room. Fig. 1 shows the schematic picture of the office room.

The UFP concentration in the indoor air of the office room and in the outdoor air was measured by means of two nano tracers Model PNT 1000. The particle counters count particles with sizes ranging from $10 \mathrm{~nm}$ to $300 \mathrm{~nm}$.

The indoor ozone level was measured by the ozone monitor BMT 930. The outdoor ozone concentration was measured by ozone monitor 2B Technologies Model 205. A multi-gas monitor B\&K, Model 1302, was used to measure the level of TVOCs (total volatile organic compounds). An Innova Model 1312 multi-gas monitor was used to measure the concentration of TVOCs of the outdoor air.

Air cleaning is one of the principal means of UFP mitigation in indoor environments [36]. The selection of the technologies was based on the popularity of the technologies in the Danish market, products' proven efficiency and novelty. Five air cleaners, which were in use for indoor air, were selected and evaluated.

The first technology was PAP (portable air purifier) that was a novel technology. As shown in Fig. 2, it comprises UV (ultraviolet) light, ozone generator and electrostatic precipitator. The technology has been invented recently and it is at the development stage. The ozone is generated by an ozone generator and reacts with contaminants in the air and generates oxidized

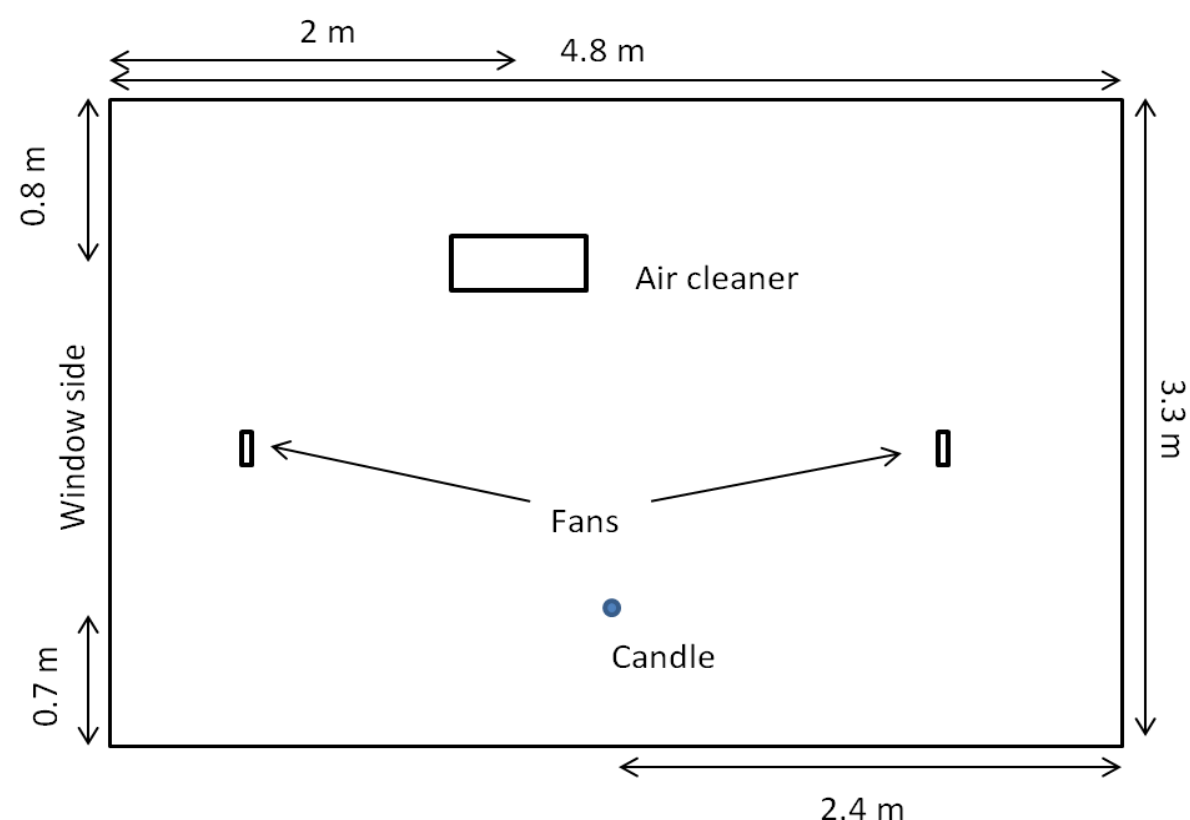

Fig. 1 Schematic picture of the office room. 


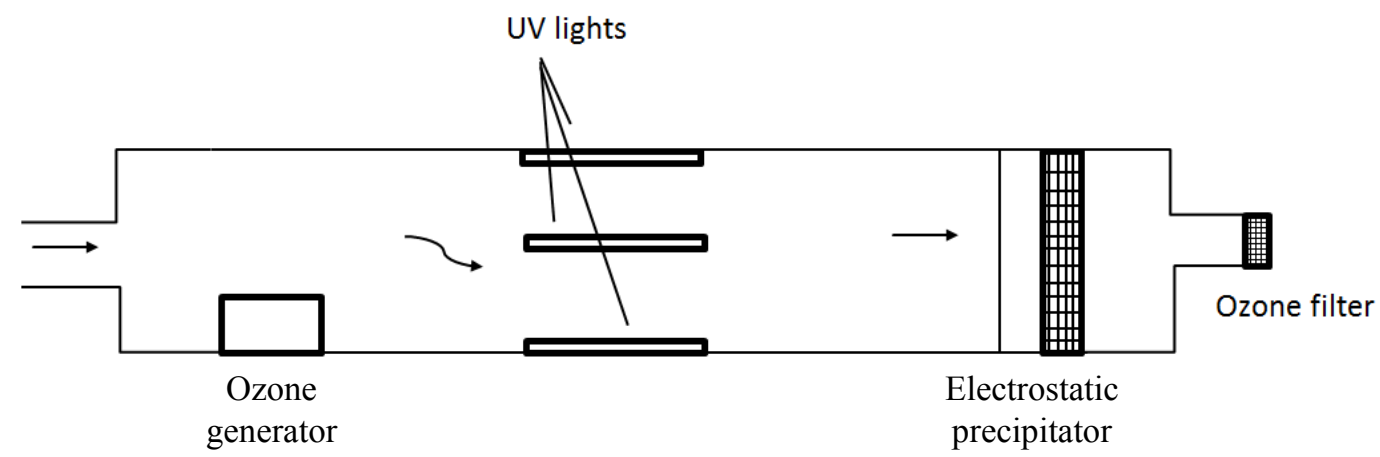

Fig. 2 Schematic view of the portable air purifier technology.

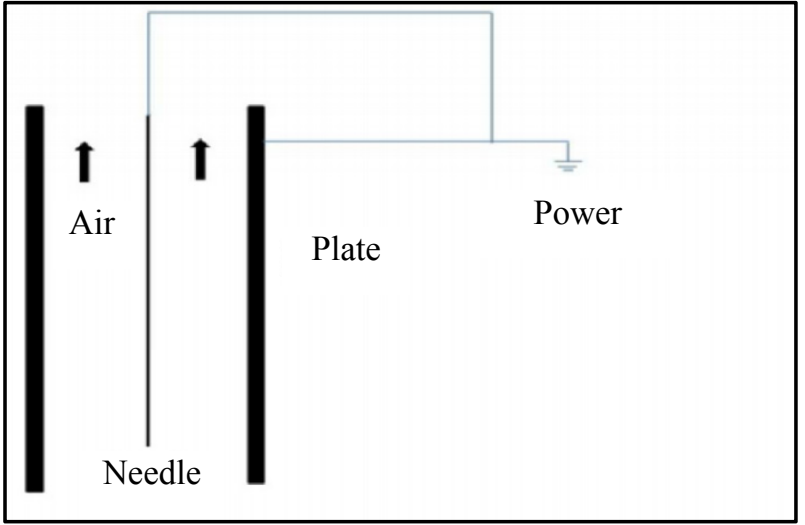

Fig. 3 Schematic view of the corona discharge ionizer technology.

substances. This process causes the particles to grow in size and to be captured in the electrostatic precipitator. An ozone filter was used at the end of the process to remove the rest of the ozone from air. The filter was made of $\mathrm{MnO}_{2}$ (manganese dioxide).

The second technology was CDI (corona discharge ionizer). As shown in Fig. 3, this technology uses a needle and a plate to discharge electrons in the air and decompose contaminants. By putting high voltage to the needle, the electrons were discharged to the air when substances are passing the corona.

The third one was NTP (non thermal plasma) which was similar to CDI but with a barrier discharger. It is a type of NTP that comprises two coaxial cylinders with a barrier at the middle of the cylinders. The barrier prevents the electrons from flowing, but they discharge, therefore causing the discharge of the air and substances to pass through the cylinders.

The fourth technology was the technology that was a fibrous filter with electrostatically charged fibers. It was a synthetic fibrous filter with the packing density of $80 \mathrm{~g} / \mathrm{m}^{2}$. Different types of EFF (electrostatic fibrous filters) have been used to clean the air in ventilation systems. The filtration efficiency of fibrous filters can change by some parameters, such as the density and thickness of filter medium, etc.. More detailed information about different methods of producing such a filter, the types of material used and its characteristics is available in the research published by ASHRAE (American Society of Heating, Refrigerating and Air Conditioning Engineers) [37].

The fifth air cleaning technology was a filter with electrostatically charged fibers. One side of the fibers was attached to a grid. The air could pass along the fibers through the gap between the fibers. Thousands of fibers were attached to a grid inside a frame. The particles were collected along the flow on the individual fibers. Therefore, this technology was denoted as 3D.

The air change rate of the room was obtained using the tracer gas decay rate method. The tracer gas $\mathrm{N}_{2} \mathrm{O}$ was injected into the room and its concentration was measured continuously. The air change rate is reported in the next section.

\section{Results}

According to the data obtained for ozone in the room, the background concentration of ozone during the measurement was between $10 \mathrm{ppb}$ to $15 \mathrm{ppb}$. The three air cleaning technologies, PAP, CDI and NTP, increased the level of ozone in the room and the two technologies, EFF and 3D filter, did not generate any ozone. 
Fig. 4 shows the ozone concentration for the three air cleaning technologies, i.e., NTP, CDI and PAP. The maximum ozone concentrations reached $52 \mathrm{ppb}$, $28 \mathrm{ppb}$ and $26 \mathrm{ppb}$ for NTP, CDI and PAP, respectively.

Fig. 5 shows UFP concentrations indoors and outdoors when NTP technology operated in the office room. The air cleaner caused no significant change in the particle concentration of the room.

The PAP technology was also placed in the middle of the room and it operated continuously. The result is shown in Fig. 6. It did not increase the UFP level in the room. The maximum UFP level for this technology was $8,000 \mathrm{UFP} / \mathrm{cm}^{3}$.

CDI generated ozone, but it did not increase the UFP level in the office room. As shown in Fig. 4, the ozone concentration reached 25 ppb. The particle concentrations indoors and outdoors for the case of CDI technology are shown in Fig. 7. According to the figure, the UFP concentration was reduced after the air cleaner was turned on.

Two other technologies, i.e., EFF and 3D filter, did not generate ozone in the office room and consequently they did not have any effect on UFP concentration.

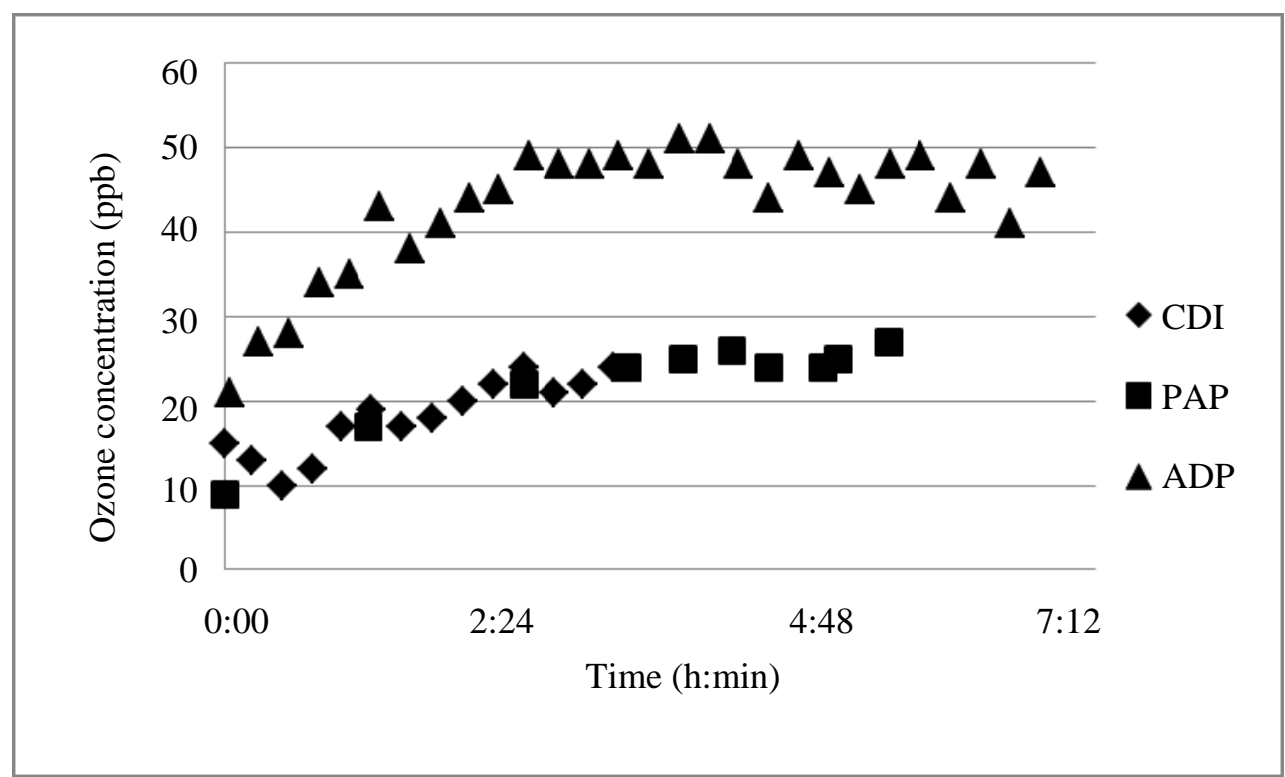

Fig. 4 Ozone concentrations for NTP, CDI and PAP.

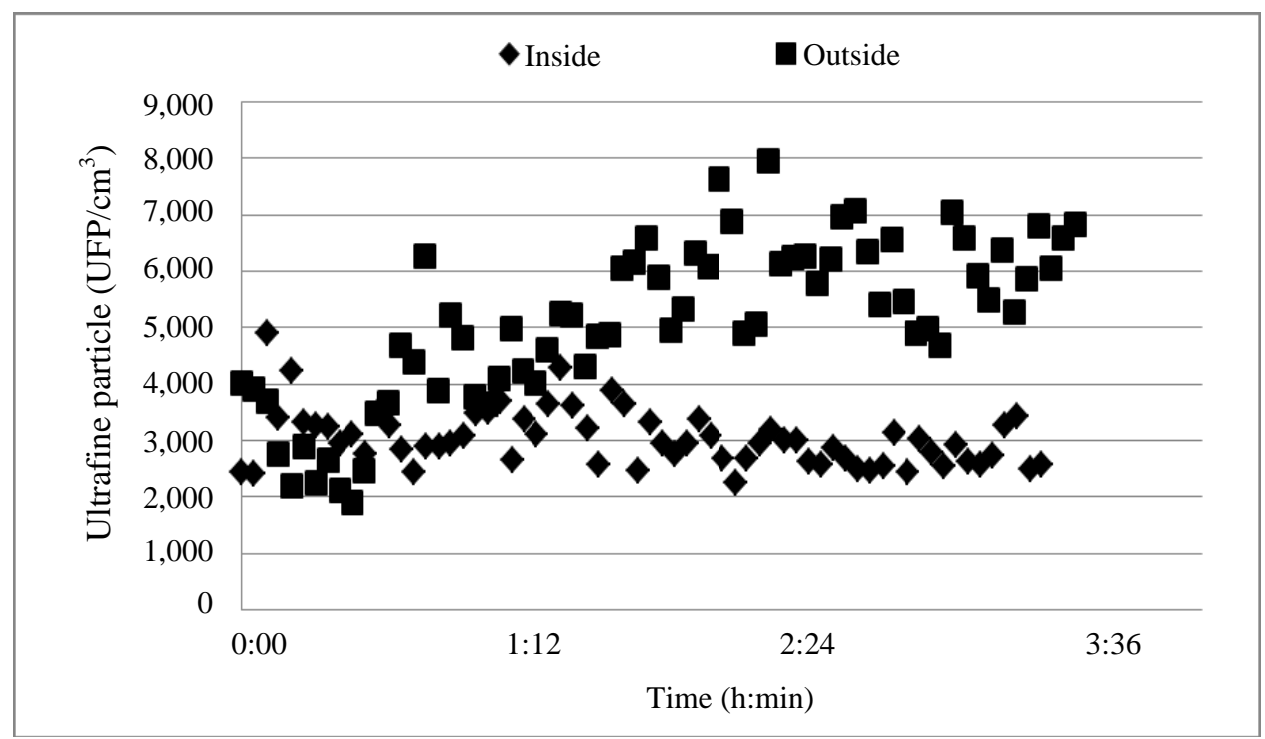

Fig. 5 UFP concentrations in the indoor air and outdoor air for NTP technology. 


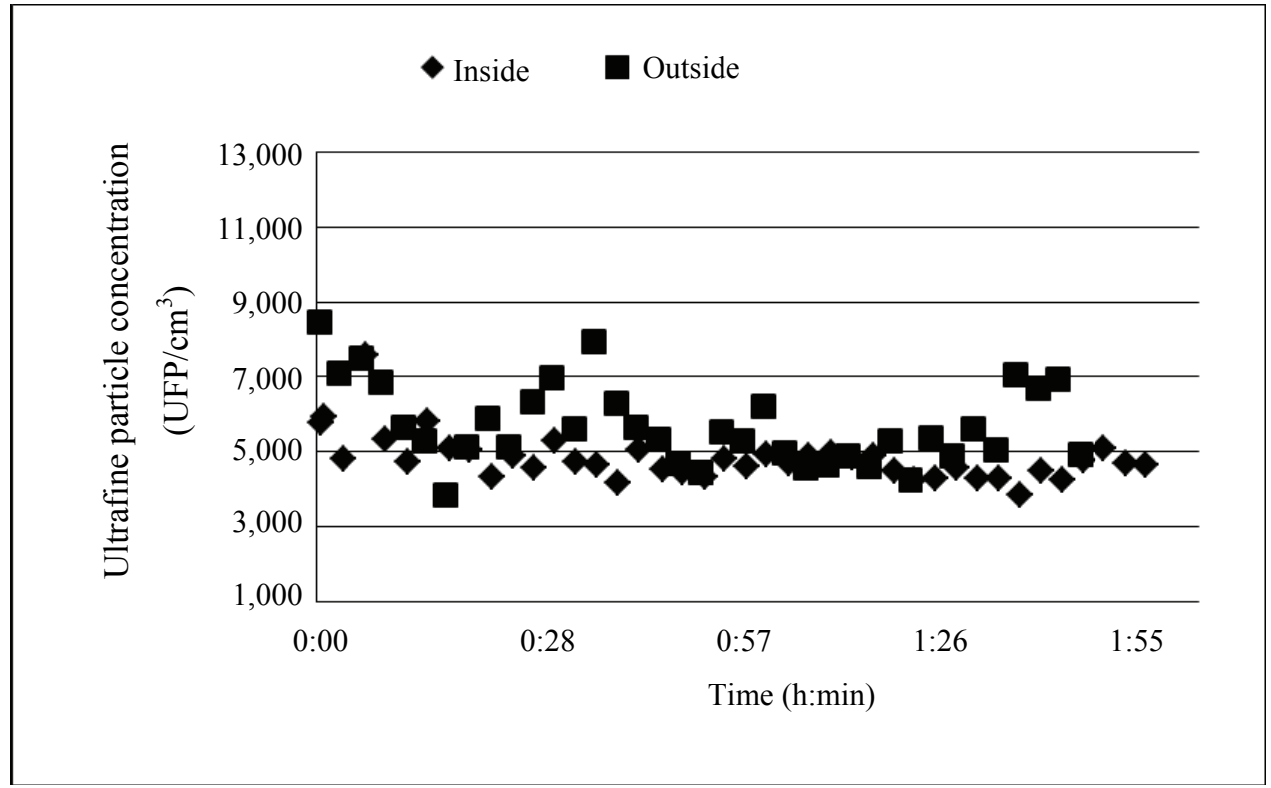

Fig. 6 UFP concentrations in the indoor air and outdoor air for PAP technology.

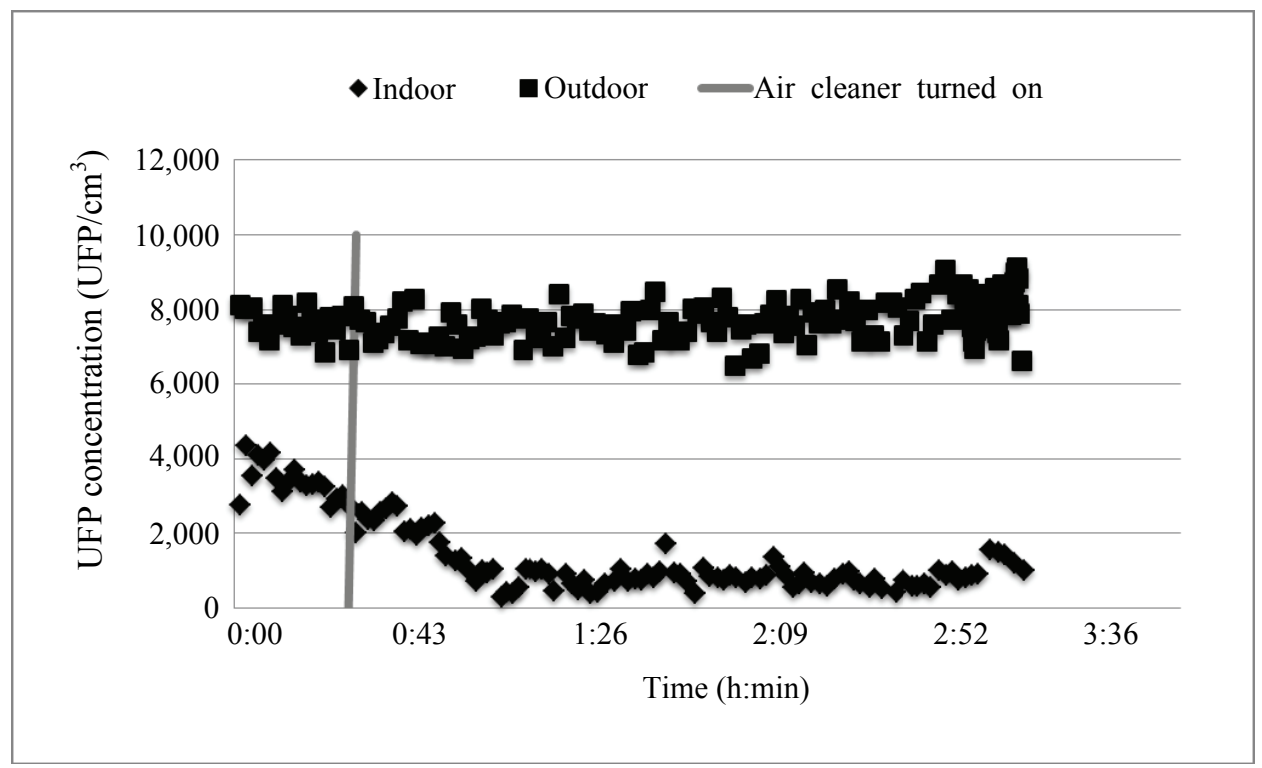

Fig. 7 UFP concentrations in the indoor air and outdoor air for CDI technology.

The logged data of TVOCs during the experiments of the three air cleaning technologies PAP, CDI and NTP are shown in Fig. 8.

Table 1 shows the CADR and the effectiveness $(\varepsilon)$ of the air cleaning technologies in removing UFPs which are obtained by Eq. (1). The coefficient of determination values $\left(R^{2}\right)$ for the trendlines fits the decay curves for removal abilities of air cleaner $\left(\lambda_{a c}\right)$ and removal ability of ventilation and deposition $\left(\lambda_{v}+\right.$ $\lambda_{d}$ ) is between 0.94 and 0.98 . The air change rates of the room for two cases, first with running air cleaner in the room and second without air cleaner, are reported in Table 1.

\section{Discussions}

The prospective maximum concentration of ozone can change depending on the ventilation rate of an office room, the ozone generation rate of an air cleaner and the total removal constant of the ozone in a room.

The three air cleaning technologies, NTP, CDI and 


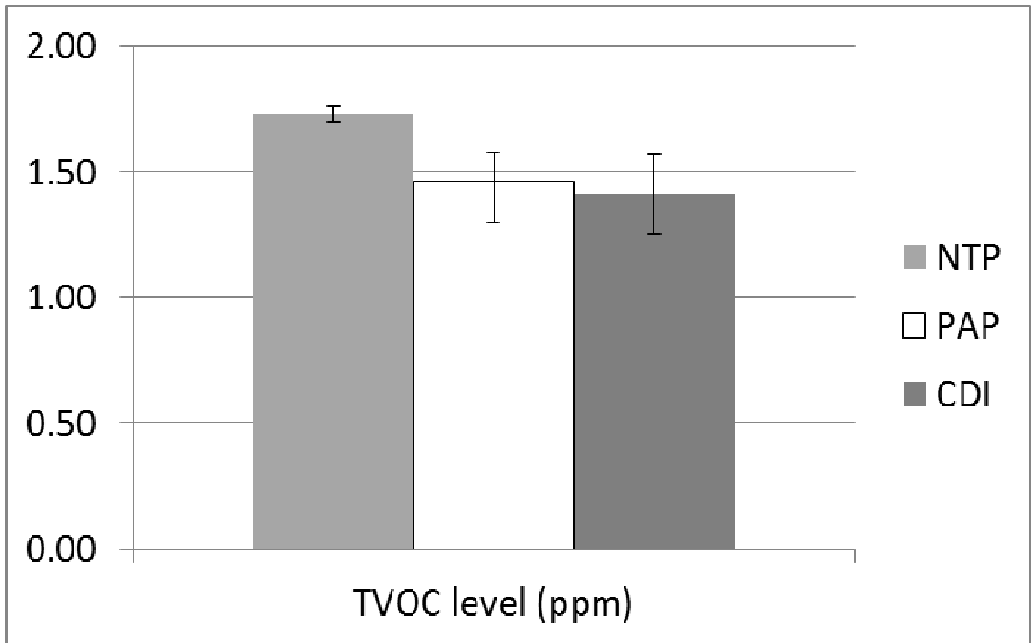

Fig. 8 Level of TVOCs in the indoor air for the three air cleaners PAP, CDI and NTP.

Table 1 Effectiveness of the air cleaners in removing UFPs.

\begin{tabular}{llllrl}
\hline Air cleaners & $\begin{array}{l}\text { Average air change rate } \\
\text { of the room }\left(\mathrm{h}^{-1}\right)\end{array}$ & $\begin{array}{l}\text { UFP decay rate of system } \\
\text { with air cleaner } \lambda_{v}+\lambda_{d}\left(\mathrm{~h}^{-1}\right)\end{array}$ & $\begin{array}{l}\text { UFP decay rate of system } \\
\text { without air cleaner } \lambda_{a c}\left(\mathrm{~h}^{-1}\right)\end{array}$ & CADR & Effectiveness $(\varepsilon)$ \\
\hline NTP & 0.45 & 1.14 & 0.86 & 13 & 0.20 \\
CDI & 0.60 & 3.56 & 1.24 & 110 & 0.39 \\
PAP & 0.40 & 1.28 & 0.86 & 20 & 0.25 \\
EFF & 0.63 & 5.20 & 1.40 & 180 & 0.42 \\
3D filter & 0.60 & 3.70 & 1.23 & 117 & 0.40 \\
\hline
\end{tabular}

Table 2 Ozone removal rate for three air cleaners in the office room.

\begin{tabular}{|c|c|c|c|c|c|}
\hline \multirow{2}{*}{ Air cleaners } & \multirow{2}{*}{ Nominal flow rate $\left(\mathrm{m}^{3} / \mathrm{h}\right)$} & \multicolumn{2}{|c|}{ Ozone level (ppb) } & \multirow{2}{*}{$-G\left(\mathrm{mg} / \mathrm{m}^{3} \mathrm{~s}\right)$} & \multirow{2}{*}{$\lambda_{o}\left(\mathrm{~h}^{-1}\right)$} \\
\hline & & Inlet & Outlet & & \\
\hline NTP & 140 & 9 & 14 & 1.400 & 0.28 \\
\hline CDI & 300 & 9 & 12 & 1.800 & 0.68 \\
\hline PAP & 43 & 9 & 10 & 0.086 & 0.03 \\
\hline
\end{tabular}

PAP, increased the level of ozone in a clean room according to the measurements in the laboratory environment and measurements in duct reported in a previously published paper [20]. In addition, it shows that the technologies that generate ozone can cause the UFP concentration to increase in a laboratory room. Due to the fact that the generated ozone can react with unsaturated VOCs and can generate UFPs.

With having the data of the ozone concentration before and after the air cleaning technologies [20] and by using Eq. (3) with Eq. (6), it is possible to calculate the ozone removal rate for the air cleaners in the office room as it is shown in Table 2 .

As it is clear in Eq. (5), the maximum ozone concentration of indoor air depends on the $\lambda_{0}$.
Accordingly, there was a risk that an ozone-initiating air cleaner would exceed the maximum allowable level of ozone and harm the residents of the room, since the removal rate of ozone $\lambda_{o}$ depends on the size of the room, ventilation rate of the room, the ability of air cleaner in removing ozone and wall material.

The highest $\lambda_{o}$ belongs to the CDI technology. One reason seems to be that it has the highest flow rate, i.e., $300 \mathrm{~m}^{3} / \mathrm{h}$. This high flow rate caused higher mixing in the room which itself helped the process of adsorption of the ozone molecules to the wall surfaces. PAP had the lowest removal rate. Since the flow rate of this air cleaner was low in comparison with the two others, it had a low $\lambda_{o}$.

In another study by Tung [38], the background 
ozone level was taken into account by adding to the equation of the $C_{m}$. In addition, the curve of the dependency of $C_{m}$ to the air change rate of the room has been shown for the evaluated air cleaners. The curve is a hyperbolic curve, meaning that by increasing the air change rate of the room, the $C_{m}$ decreases.

Despite the previous results [20], the three first air cleaning technologies did not increase the particle concentration in the office room. The main hypothesis is that there were not enough unsaturated VOC molecules in the office room to react with ozone molecules and consequently generate particles.

The concentration of the VOCs depended on the air velocity in the room, age of building material, VOC concentration of supplied air, temperature and humidity of the air $[39,40]$. A possibility could be that, in this office room, any kind of perfumed products such as detergents has not been used. Therefore, there was not this kind of unsaturated VOCs. The main difference was that the office room was not refurbished for about two decades. Some of the sources of VOCs were wall pigments, cardboards and new furniture. None of these sources were available in this room. In addition, the building material had lower emission rate of VOCs than a new material, instead, the wall material could act as sink for VOCs coming from outdoor air and the VOCs adsorbed to the wall surfaces [41]. However, in order to ensure that this is the main reason, other measurements of the concentration of specific VOCs are needed.

The $C A D R$ of the five air cleaning technologies are reported in Table 1. It is shown in the table that the electrostatic fibrous filter EFF has the highest effectiveness. CDI and 3D filters have similar effectiveness. The side effect of the CDI technology is that it generates ozone and as mentioned before, there is a risk of exceeding the maximum allowable ozone concentration in an office room. The result shown in Table 1 should be considered with a caution that the experiments were performed in an office room, the ventilation rate was not constant and the outdoor concentration had an effect on the indoor concentration due to the infiltration.

It seems that the electrostatic filters are promising air cleaning technologies as they remove UFPs efficiently while the pressure drop in them is low. According to the measurements on EFF and 3D filter, they cause pressure drops of $5 \mathrm{~Pa}$ and $7 \mathrm{~Pa}$, respectively.

\section{Conclusions}

Five air cleaning technologies including three ozone initiating technologies and two filters were evaluated. It is concluded that the maximum ozone concentration, caused by an air cleaner in an office room, depends on the size of the room and ventilation rate. It is also concluded that the generation of particles by ozone-initiating air cleaning technology depends on the age of the wall material. According to this study, an electrostatic fibrous filter is suggested as an air cleaning technology that can clean the air effectively with no risk of ozone exposure.

\section{Acknowledgments}

The authors gratefully appreciate the financial support given by ELFORSK, a Danish energy program of research and development in energy efficiency. The authors also thankfully acknowledge the financial support provided by Lindab ventilation $\mathrm{A} / \mathrm{S}$ and ELFI Elektrofilter AB.

\section{References}

[1] Afshari, A., Matson, U., and Ekberg, L. E. 2005. "Characterization of Indoor Sources of Fine and Ultrafine Particles: A Study Conducted in a Full-Scale Chamber." Indoor Air 15: 141-50.

[2] Sangiorgi, G., Ferrero, L., Ferrini, B. S., lo Porto, C., Perrone, M. G., Zangrando, R., Gambaro, A., Lazzati, Z., and Bolzacchini, E. 2013. "Indoor Airborne Particle Sources and Semi-volatile Partitioning Effect of Outdoor Fine PM in Offices." Atmospheric Environment 65: 205-14.

[3] Song, S., Lee, K., Lee, Y. M., Lee, J. H., Lee, S. I., Yu S. D., Paek, D. 2011. "Acute Health Effects of Urban Fine and Ultrafine Particles on Children with Atopic Dermatitis." Environmental Research 111: 394-9. 
[4] Strak, M., Janssen, N. A., Godri, K. J., Gosens, I., Mudway, I. S., Cassee, F. R., Lebret, E., Kelly, F. J., Harrison, R. M., Brunekreef, B., Steenhofm, M., and Hoek, G. 2012. "Respiratory Health Effects of Airborne Particulate Matter: The Role of Particle Size, Composition, and Oxidative Potential-The RAPTES Project." Environmental Health Perspectives 120: 1183-9.

[5] Buonanno, G., Marks, G. B., and Morawska, L. 2013. "Health Effects of Daily Airborne Particle Dose in Children: Direct Association between Personal Dose and Respiratory Health Effects.” Environmental Pollution 180: 246-50.

[6] Utell, M. J., and Frampton, M. W. 2000. "Acute Health Effects of Ambient Air Pollution: The Ultrafine Particle Hypothesis." Journal of Aerosol Medicine 13: 355-9.

[7] Bräuner, E. V., Forchhammer, L., Møller, P., Barregard, L., Gunnarsen L, Afshari, A., Wahlin, P., Glasius, M., Dragsted, L. O., Basu, S., Raaschou-Nielsen, O., and Loft, S. 2008. "Indoor Particles Affect Vascular Function in the Aged: An Air Filtration-Based Intervention Study." American Journal of Respiratory and Critical Care Medicine 177: 419-25.

[8] Penttinen, P., Timonen, K. L., Tiittanen, P., Mirme, A., Ruuskanen, J., and Pekkanen, J. 2001. "Ultrafine Particles in Urban Air and Respiratory Health among Adult Asthmatics." European Respiratory Journal 17: 428-35.

[9] Knibbs, L. D., Cole-Hunter, T., and Morawska, L. 2011. "A Review of Commuter Exposure to Ultrafine Particles and Its Health Effects." Atmospheric Environment 45: 2611-22.

[10] Knol, A. B., de Hartog, J. J., Boogaard, H., Slottje P, Van der Sluijs, J. P., Lebret E, et al. "Expert Elicitation on Ultrafine Particles: Likelihood of Health Effects and Causal Pathways." Particle and Fibre Toxicology 6: 19.

[11] Neidell, M. J. 2004. "Air Pollution, Health, and Socio-economic Status: The Effect of Outdoor Air Quality on Childhood Asthma." Journal of Health Economics 23: 1209-36.

[12] Chen, T. M., Gokhale, J., Shofer, S., and Kuschner, W. G. 2007. "Outdoor Air Pollution: Ozone Health Effects." American Journal of Medicine Science 333: 244-8.

[13] Wainman, T., Zhang, J., Weschler, C. J., and Lioy, P. J. 2000. "Ozone and Limonene in Indoor Air: A Source of Submicron Particle Exposure.” Environmental Health Perspectives 108: 1139-45.

[14] Fan, Z., Lioy, P., Weschler, C., Fiedler, N., Kipen, H., and Zhang, J. 2003. "Ozone-Initiated Reactions with Mixtures of Volatile Organic Compounds under Simulated Indoor Conditions." Environmental Science Technology 37: 1811-21.
[15] Edwards, R., Jurvelin, J., and Koistinen, K. 2001. "VOC Source Identification from Personal and Residential Indoor, Outdoor and Workplace Microenvironment Samples in EXPOLIS-Helsinki, Finland." Atmospheric Environment 35: 4829-41.

[16] Wolkoff, P. 1998. "Impact of Air Velocity, Temperature, Humidity, and Air on Long-term VOC Emissions from Building Products." Atmospheric Environment 32: 2659-68

[17] Afshari, A., Lundgren, B., and Ekberg, L. 2003. "Comparison of Three Small Chamber Test Methods for the Measurement of VOC Emission Rates from Paint." Indoor Air 13: 156-65.

[18] Shaughnessy, R. J., and Sextro, R. G. 2006. "What Is an Effective Portable Air Cleaning Device? A Review." Journal of Occupational and Environmental Hygiene 3: 169-81.

[19] Zhang, Y., Mo, J., Li, Y., Sundell, J., Wargocki, P., Zhang, J., et al. 2011. "Can Commonly-Used Fan-Driven Air Cleaning Technologies Improve Indoor Air Quality? A Literature Review." Atmospheric Environment 45: 4329-43.

[20] Ardkapan, S., Afshari, A., Bergsøe, N. C., and Johnson, M. S. 2011. "Evaluating the Operation of Three Air Cleaners Working Individually in a Clean Room." Presented at the 12th International Conference on Indoor Air Quality and Climate, Austin, Texas.

[21] Yu, K., Lee, G., Hsieh, C., and Lin, C. 2011. "Evaluation of Ozone Generation and Indoor Organic Compounds Removal by Air Cleaners Based on Chamber Tests." Atmospheric Environment 45: 35-42.

[22] Alshawa, A., Russell, A. R., and Nizkorodov, S. 2007. "Kinetic Analysis of Competition between Aerosol Particle Removal and Generation by Ionization Air Purifiers." Environment Science Technology 41: 2498-504.

[23] Waring, M. S., Siegel J. A., and Corsi, R. L. 2008. "Ultrafine Particle Removal and Generation by Portable Air Cleaners." Atmospheric Environment 42: 5003-14.

[24] Berry, D., Mainelis, G., and Fennell, D. 2007. "Effect of an Ionic Air Cleaner on Indoor/Outdoor Particle Ratios in a Residential Environment." Aerosol Science Technology 41: 315-28

[25] Hubbard, H. F., Coleman, B. K., Sarwar, G., and Corsi, R. L. "Effects of an Ozone-Generating Air Purifier on Indoor Secondary Particles in Three Residential Dwellings." Indoor Air 15: 432-44.

[26] Ardkapan, S. R., Afshari, A., Bergsøe, N. C., and Nielsen, P. V. 2013. "Evaluation of Air Cleaning Technologies Existing in the Danish Market: Experiments in a Duct and in a Test Room." Indoor Built Environment 23 (8): 1177-86. 


\section{An Experimental Study}

[27] Nazaroff, W. 2000. "Effectiveness of air cleaning technologies." In Proceedings of Healthy Buildings, 49-54.

[28] Zhang, T., Wang, S., Sun, G., Xu, L., and Takaoka, D. 2010. "Flow Impact of an Air Conditioner to Portable Air Cleaning." Build Environment 45: 2047-56.

[29] Ardkapan, S. R., Afshari, A., Nielsen, P. V., Iqbal, A., and Bergsøe, N. C. 2012. "Simulation of Particle Distribution in a Room with Air Cleaner." Presented at Healthy Buildings 2012, Brisbane, Australia.

[30] Ward, M., Siegel, J. A., and Corsi, R. L. 2005. "The Effectiveness of Stand Alone Air Cleaners for Shelter-in-Place." Indoor Air 15: 127-34.

[31] Grabarczyk, Z. 2001. "Effectiveness of Indoor Air Cleaning with Corona Ionizers." Journal of Electrostatics 51-52: 278-83.

[32] Akbar-Khanzadeh, F., Milz, S., and Ames, A. 2004. "Effectiveness of Clean Indoor Air Ordinances in Controlling Environmental Tobacco Smoke in Restaurants." Archives of Environmental Health 59: 677-85.

[33] Zhang, T., Wang, S., Sun, G., Xu, L., and Takaoka, D. 2010. "Flow Impact of an Air Conditioner to Portable Air Cleaning." Building Environment 45: 2047-56.

[34] Shi, B., Ekberg, L., Afshari, A., and Bergsøe, N. 2010. "The Effectiveness of Portable Air Cleaners against Tobacco Smoke in Multizone Residential Environments."
Presented at Clima 2010, Turkey.

[35] Niu, J. 2001. "Ozone Emission Rate Testing and Ranking Method Using Environmental Chamber." Atmospheric Environment 35: 2143-51.

[36] Zuraimi, M. S., and Tham, K. W. 2009. "Reducing Particle Exposures in a Tropical Office Building Using Electrostatic Precipitators." Building and Environment 44: 2475-85.

[37] Lehtimäki, M., Säämänen, A., and Taipale, A. RP-1189-Investigation of Mechanisms and Operating Environments that Impact the Filtration Efficiency of Charged Air Filtration Media. USA: ASHRAE.

[38] Tung, T. C. W. 2005. "Determination of Ozone Emission from a Domestic Air Cleaner and Decay Parameters using Environmental Chamber Tests." Indoor Built Environment 14: 29-37.

[39] Knudsen, H., and Kjaer, U. 1999. "Sensory and Chemical Characterization of VOC Emissions from Building Products. Impact of Concentration and Air Velocity." Atmospheric Environment 33: 1217-30.

[40] Wolkoff, P. 1995. "Volatile Organic Compounds Sources, Measurements, Emissions, and the Impact on Indoor Air Quality.” Indoor Air 5: 5-73.

[41] Hansson, P. 2003. "The Sink-Effect in Indoor Materials: Mathematical Modelling and Experimental Studies." Dissertation, Royal Institute of Technology, Sweden. 